\title{
Shear Capacity of Headed Studs in Steel-Concrete Structures: Analytical Prediction via Soft Computing
}

This paper was downloaded from TechRxiv (https://www.techrxiv.org).

LICENSE

CC BY 4.0

SUBMISSION DATE / POSTED DATE

$12-07-2020$ / 14-12-2021

CITATION

Abambres, Miguel; J, He (2020): Shear Capacity of Headed Studs in Steel-Concrete Structures: Analytical Prediction via Soft Computing. TechRxiv. Preprint. https://doi.org/10.36227/techrxiv.12645086.v2

$\mathrm{DOI}$

10.36227/techrxiv.12645086.v2 


\title{
Shear Capacity of Headed Studs in Steel-Concrete Structures: Analytical Prediction via Soft Computing
}

\author{
Miguel Abambres ${ }^{\mathrm{a} *}$, Jun $\mathrm{He}^{\mathrm{b}}$ \\ a* R\&D, Abambres' Lab, 1600-275 Lisbon, Portugal; Instituto Superior de Educação e Ciências (ISEC-Lisboa), \\ School of Technologies and Engineering, 1750-142, Lisbon, Portugal. \\ abambres@netcabo.pt \\ ${ }^{\mathrm{b}}$ School of Civil Eng, Changsha University of Science and Technology, 410114, Changsha, PR China
hejun@csust.edu.cn
}

\begin{abstract}
Headed studs are commonly used as shear connectors to transfer longitudinal shear force at the interface between steel and concrete in composite structures (e.g., bridge decks). Code-based equations for predicting the shear capacity of headed studs are summarized. An artificial neural network (ANN)-based analytical model is proposed to estimate the shear capacity of headed steel studs. 234 push-out test results from previous published research were collected into a database in order to feed the simulated ANNs. Three parameters were identified as input variables for the prediction of the headed stud shear force at failure, namely the steel stud tensile strength and diameter, and the concrete (cylinder) compressive strength. The proposed ANN-based analytical model yielded, for all collected data, maximum and mean relative errors of $3.3 \%$ and $0.6 \%$, respectively. Moreover, it was illustrated that, for that data, the neural network approach clearly outperforms the existing code-based equations, which yield mean errors greater than $13 \%$.
\end{abstract}

Keywords: Shear Connectors; Headed Studs; Push-Out Test; Shear Capacity; Artificial Neural Networks; Analytical Model; Steel-Concrete Structures.

\section{Introduction}

Steel-concrete composite structures make an effective utilization of concrete in the compression zone and steel in the tension counterpart, offering several advantages. The 
Abambres M, He J (2019). Shear Capacity of Headed Studs in

Steel-Concrete Structures: Analytical Prediction via Soft Computing, hal-02074833

(C) 2019 by Abambres M, He J (CC BY 4.0)

primary one is the high strength-to-weight ratio as compared to conventional reinforced concrete (RC) structures. They also offer greater flexural stiffness, speedier and more flexible construction, ease of retrofitting and repair, and higher durability (Shanmugam and Lakshmi 2001, He et al.2010, Lin et al. 2014). In steel-concrete composite structures, shear connectors (e.g., angles, channel sections, headed studs, perforated ribs) are essential in all composite members in order to guarantee the effectiveness of their behavior in terms of strength and deformability. Those connectors, located in the steel-concrete interface, must be able to effectively transfer the stresses occurring between both materials (Lam and El-Lobody 2005, Colajanni et al. 2014, He et al. 2014).

The load-slip performance of shear connectors has been established from push-out tests, first devised in Switzerland in the early 1930s (Roš 1934). Following the development of the electric drawn arc stud welding apparatus in the early 1950s, the headed stud connector became one of the most popular shear connector types owing to their simple and quick installation and superior ductility when compared with other types of connectors. The latter was attested by extensive experimental investigations in North America between 1951 and 1959 at the University of Illinois (Newmark et al. 1951, Viest 1956) and Lehigh University (Thurlimann 1959). Newmark et al. (1951) tested the behavior of shear connectors by beam and push-out experiments, having shown that the stud was a perfectly flexible connector in a wide variety of scenarios (a large number of variables were assessed). Viest (1956) conducted 12 push-out tests and observed three types of failure: (i) steel-driven, where the stud reaches its yield point and fails, (ii) concrete-driven, where the concrete surrounding the headed stud crushes, and (iii) 
Abambres M, He J (2019). Shear Capacity of Headed Studs in

Steel-Concrete Structures: Analytical Prediction via Soft Computing, hal-02074833

(C) 2019 by Abambres M, He J (CC BY 4.0)

mixed failures, which are a combination of the former. Furthermore, he proposed one of the first formulas to assess the shear strength of headed studs. Thurlimann (1959), Driscoll and Slutter (1961), and Slutter and Driscoll (1965) tested a series of beam and push-out specimens, which proved that stud connectors had a higher shear strength in beams than in push-out specimens, meaning the results from push-out tests could be taken as a conservative approximation of the actual strength in beams; moreover, a formula was obtained to calculate the shear resistance of stud connectors as function of the concrete strength and stud diameter. Chinn (1965) and Steele (1967) developed push-out tests on lightweight composite slabs. Davies (1967) tested twenty 'half-scale' push-out specimens to study the effects of varying the number, spacing and pattern of the welded studs, and proved that the 'standard' specimen with two welded stud connectors arranged across steel flanges exhibits superior performance throughout their loading. Mainstone and Menzies (1967) carried out tests on 83 push-out specimens covering the behavior of headed anchors under both static and fatigue loads. Johnson et al. (1969) measured the shear performance of studs and developed a calculation model based on push-out tests. Menzies (1971) performed some push-out tests about the effect of concrete strength and density on the static and fatigue capacities of stud connectors. Ollgaard et al. (1971) guessed the shear resistance of the stud to be only dependent on concrete strength and Young's modulus, and on the stud diameter. Oehlers \& Coughlan (1986), Oehlers (1989), and Oehlers \& Bradford (1999) analyzed 116 specimens failing through the shank, and proposed formulas to calculate the elastic shear stiffness, the slip at $50 \%$ of the ultimate load (assumed to be the limit of the linear load-slip response), and the ultimate load. Oehlers \& 
Abambres M, He J (2019). Shear Capacity of Headed Studs in

Steel-Concrete Structures: Analytical Prediction via Soft Computing, hal-02074833

(C) 2019 by Abambres M, He J (CC BY 4.0)

Bradford (1995) indicated that short steel studs experimentally show a lower shear strength than the long counterpart. The variation with stud length has been recognized in some national standards (e.g., BSI 1979). More recently, extensive experimental research on the shear behavior of stud connectors under static, cyclic (Gattesco and Giuriani 1996) or fatigue (Dogan and Roberts 2012) loading has been carried out. Parameters like (i) concrete strength and types (Valente and Cruz 2009, Kim et al. 2015, Han et al. 2017), (ii) stud diameter (Badie et al. 2002, Shim et al. 2004), (iii) biaxial loading effect (Xu et al. 2015), (iv) quantity of studs (Xue et al. 2008, 2012), and (v) the boundary and loading conditions (Lin et al. 2014), were assessed in those studies. An and Cederwall (1996) employed push-out tests and concluded that the concrete compressive strength significantly affects the stud shear capacity. Topkaya et al. (2004) tested 24 specimens in order to describe the behavior of headed studs at early concrete ages. Shim et al. (2004) and Lee et al. (2005) investigated the static and fatigue behavior of large stud shear connectors up to $30 \mathrm{~mm}$ in diameter, which were beyond the limitation of current design codes. A new stud system fastened with high strength pins was experimentally investigated by Mahmood et al. (2009). Xue et al. (2012) investigated the different behaviors between single-stud and multi-stud connectors. Marko et al. (2013) studied the different behaviors between bolted and headed stud shear connectors.

According to the aforementioned research, the shear bearing capacity of studs depends on many factors, including the material and diameter of the stud itself, and properties of the surrounding concrete slab. These factors are all included in several design codes (e.g., AISC 1978, BSI 1978, CEN 2005b, AASHTO 2014, MC-PRC and GAQSIQ-PRC 2003). Tables 
Abambres M, He J (2019). Shear Capacity of Headed Studs in

Steel-Concrete Structures: Analytical Prediction via Soft Computing, hal-02074833

(C) 2019 by Abambres M, He J (CC BY 4.0)

providing allowable horizontal shear load of headed studs as function of the stud diameter and concrete strength appeared in the AISC Specification (1961). The effects of a metal deck on the shear strength of headed studs was added in the AISC Specification (1978), and the one from 1993 (AISC 1993) adopted Ollgaard's formula (1971) to compute the shear strength of headed steel studs. In Europe, the draft of Eurocode 4 (CEC 1985) proposed key reliability studies that account for the resistance of stud connectors, later undertaken by Roik et al. (1989), followed by Stark and van Hove (1991), using a procedure (Bijlaard et al. 1988, CEN 1998) that was later updated and implemented within EN 1990 (CEN 2005a). Based on results of 75 push-out tests, those studies demonstrated that a partial factor $\gamma_{v}=1.25$ was appropriate for stud diameters between 15.9 and $22 \mathrm{~mm}$, and mean compressive cylinder strengths between 16.6 and $59 \mathrm{MPa}$, which broadly corresponded to the concrete strength classes $\mathrm{C} 12 / 15$ and C50/60 given in the draft Eurocode 4 (CEC 1985) and Eurocode 2 (CEC 1984) at the time. However, last versions of Eurocode 4 (CEN 2004b, CEN 2005b) cover a wider range of concrete strength classes (C20/25 to C60/75) and stud diameters (16 to $25 \mathrm{~mm}$ ). As for the Eurocode 2 (CEN 2004a), it allows classes between C12/15 and C90/105.

While some numerical and theoretical investigations have showed that specifications in AASHTO (2014) and Eurocode 4 (CEN 2004b) usually overestimate headed stud shear capacity (Nguyen and Kim, 2009), Pallarés and Hajjar (2010) and Han et al. (2015) have attested that Eurocode 4 (CEN 2004b) is conservative. In order to effectively (accurately and efficiently) estimate the shear capacity of headed steel studs, this paper proposes the use of artificial neural networks (also referred in this manuscript as ANN or neural nets). The proposed ANN was 
Abambres M, He J (2019). Shear Capacity of Headed Studs in

Steel-Concrete Structures: Analytical Prediction via Soft Computing, hal-02074833

(C) 2019 by Abambres M, He J (CC BY 4.0)

designed based on 234 push-out test results available to date in the literature (see section 2). The focus of this study was not to understand the mechanics underlying the shear behavior of headed studs, but to propose an analytical ANN-based model that can be then easily implemented in any computer language by any interested practitioner or researcher.

\section{Data Gathering}

Determining shear connector behavior in a steel-concrete joint is usually achieved by using push-out tests. Their setup is made of a steel profile that is connected to two concrete slabs through the shear connectors, welded to profile flanges as shown in Fig. 1(a). Several push-out tests have been conducted on headed steel studs. The 234-point dataset (available in Developer 2018a) used to feed the ANN software employed in this work was assembled from the following experimental results: Viest (1956), Driscoll and Slutter (1961), Slutter and Driscoll (1965), Ollgaard et al. (1971), Menzies (1971), Hawkins (1973), Oehler and Johnson (1987), Hiragi et al. (2003), Shim et al. (2004), Zhou et al. (2007), Xue et al. (2008, 2012), Pallarés and Hajjar (2010), and Wang (2013).

Through an extensive data analysis on the aforementioned experimental results, it was decided to make the shear capacity of a headed steel stud dependent on the following three variables: (i) stud shank diameter, (ii) concrete cylinder compressive strength, and (iii) steel stud tensile strength, since those were the major parameters affecting the shear failure of headed steel studs. Way less relevant parameters were found to be the yield stress of both materials, the connector length and arrangement (spacing, pattern), the weld quality and dimensions, and the friction properties and 
Abambres M, He J (2019). Shear Capacity of Headed Studs in

Steel-Concrete Structures: Analytical Prediction via Soft Computing, hal-02074833

(C) 2019 by Abambres M, He J (CC BY 4.0)

orientation of the steel-concrete interface during concreting. For instance, shear capacity is slightly influenced by stud length when the length-to-diameter ratio is larger than 4 . In this study, all selected stud specimens have a length-to-diameter ratio greater than 4. Fig. 1 depicts the input (in green) and target/output (in red) variables considered in all ANN simulations, and Tab. 1 defines those variables, their position in the ANN layout, and shows some stats on their values. One recalls that the dataset considered in ANN simulations is available in Developer (2018a).

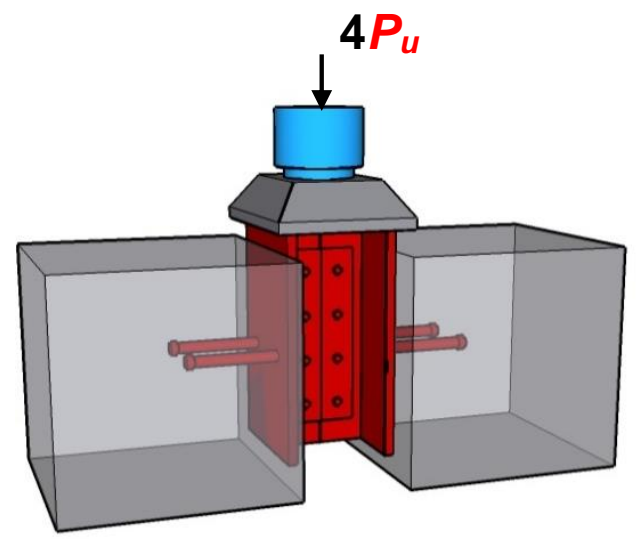

(a)

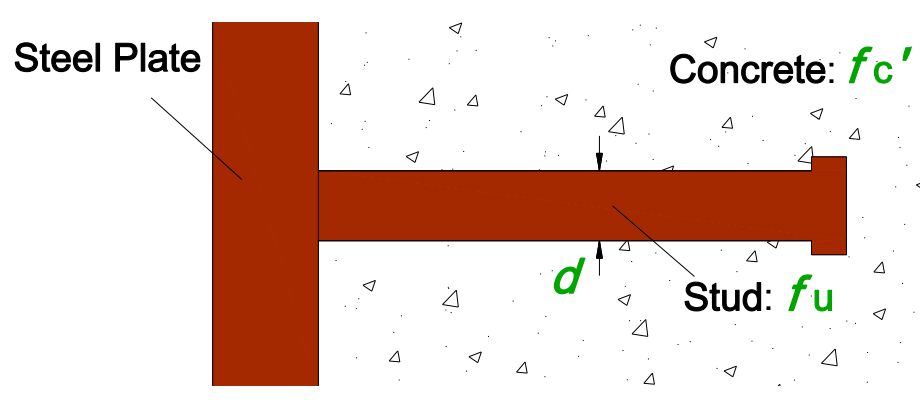

(b)

Fig. 1. Input (in green) and target (in red) variables: (a) push-out test specimen, (b) headed stud.

Tab. 1. Variables (and some stats on their values) considered for ANN simulations.

\begin{tabular}{|c|c|c|c|c|c|c|}
\hline \multirow{2}{*}{\multicolumn{3}{|c|}{ Input variables }} & \multirow{3}{*}{$\begin{array}{c}\begin{array}{c}\text { ANN } \\
\text { input node }\end{array} \\
1\end{array}$} & \multicolumn{3}{|c|}{ Values } \\
\hline & & & & \multirow{2}{*}{$\frac{\min }{9.5}$} & \multirow{2}{*}{$\frac{\max }{30}$} & \multirow{2}{*}{$\frac{\text { average }}{20.4}$} \\
\hline Geometry & $d(\mathrm{~mm})$ & Steel Stud Shank Diameter & & & & \\
\hline \multirow[t]{2}{*}{ Material } & $f_{c}{ }^{\prime}(\mathrm{MPa})$ & $\begin{array}{l}\text { Concrete (cylinder) } \\
\text { Compressive Strength }\end{array}$ & 2 & 18.3 & 109.3 & 44.6 \\
\hline & $f_{u}(\mathrm{MPa})$ & Steel Stud Tensile Strength & 3 & 305.7 & 595 & 448.4 \\
\hline \multirow{2}{*}{\multicolumn{3}{|c|}{ Target variable }} & \multirow{2}{*}{$\begin{array}{c}\text { ANN } \\
\text { output node }\end{array}$} & \multicolumn{3}{|c|}{ Values } \\
\hline & & & & $\min$ & $\max$ & average \\
\hline $\begin{array}{c}\text { Stud } \\
\text { Strength }\end{array}$ & $P_{u}(\mathrm{kN})$ & Shear Force at Failure & 1 & 26.2 & 415 & 156.1 \\
\hline
\end{tabular}


Abambres M, He J (2019). Shear Capacity of Headed Studs in

Steel-Concrete Structures: Analytical Prediction via Soft Computing, hal-02074833

(C) 2019 by Abambres M, He J (CC BY 4.0)

\section{Artificial Neural Networks}

\subsection{Brief Introduction}

One of the six disciplines of Artificial Intelligence (AI) that allows machines to act humanly is Machine Learning (ML), which aims to 'teach' computers how to perform tasks by providing examples of how they should be done (Hertzmann and Fleet 2012). The world is quietly being reshaped by ML, being the Artificial Neural Network (also referred in this manuscript as ANN or neural net) its first-born (McCulloch and Pitts 1943), most effective (Hern 2016), and most employed (Wilamowski and Irwin 2011, Prieto et. al 2016) technique, virtually covering any field of knowledge. Concerning functional approximation, ANN-based solutions often outperform those provided by traditional approaches, like the multi-variate nonlinear regression, besides not requiring knowledge on the function shape being approximated (Flood 2008).

The general ANN structure consists of several nodes grouped in $L$ vertical layers (input layer, hidden layers, and output layer) and connected between layers, as illustrated in Fig. 2. Associated to each node (or neuron) in layers 2 to $L$ is a linear or nonlinear transfer function, which receives an input and transmits an output. All ANNs implemented in this work are called feedforward, since data feeding the input layer flows in the forward direction only, as exemplified in Fig. 2 (see the black arrows).

For a more thorough introduction on ANNs, the reader should refer to Haykin (2009) or Wilamowski and Irwin (2011). 
Abambres M, He J (2019). Shear Capacity of Headed Studs in

Steel-Concrete Structures: Analytical Prediction via Soft Computing, hal-02074833

(C) 2019 by Abambres M, He J (CC BY 4.0)

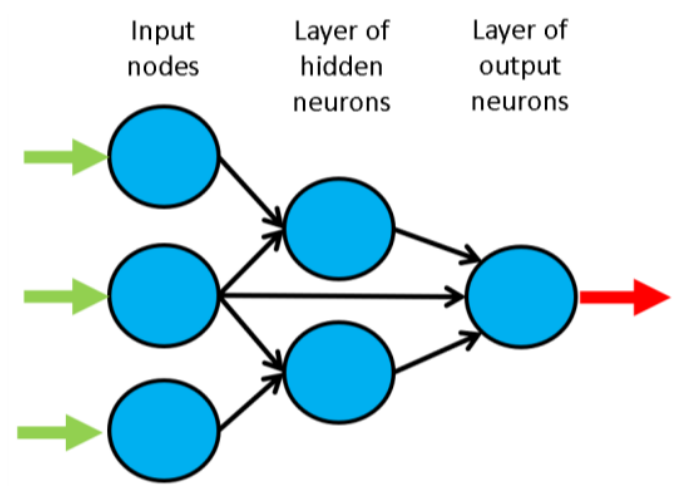

Fig. 2. Example of a feedforward ANN with node structure 3-2-1.

\subsection{Learning}

Learning is nothing else than determining network unknown parameters through some algorithm in order to minimize network's performance measure, typically a function of the difference between predicted and target (desired) outputs. When ANN learning is iterative in nature, it consists of three phases: (i) training, (ii) validation, and (iii) testing. From previous knowledge, examples or data points are selected to train the network, grouped in the so-called training dataset. During an iterative learning, while the training dataset is used to tune network unknowns, a process of cross-validation takes place by using a set of data completely distinct from the training counterpart (the validation dataset), so that the generalization performance of the network can be attested. Once 'optimum' network parameters are determined, typically associated to a minimum of the validation performance curve (called early stop - see Fig. 3), many authors still perform a final assessment of model's accuracy, by presenting to it a third fully distinct dataset called 'testing'. Heuristics suggests that early stopping avoids overfitting, i.e. the loss of ANN's generalization ability. 
Abambres M, He J (2019). Shear Capacity of Headed Studs in

Steel-Concrete Structures: Analytical Prediction via Soft Computing, hal-02074833

(C) 2019 by Abambres M, He J (CC BY 4.0)

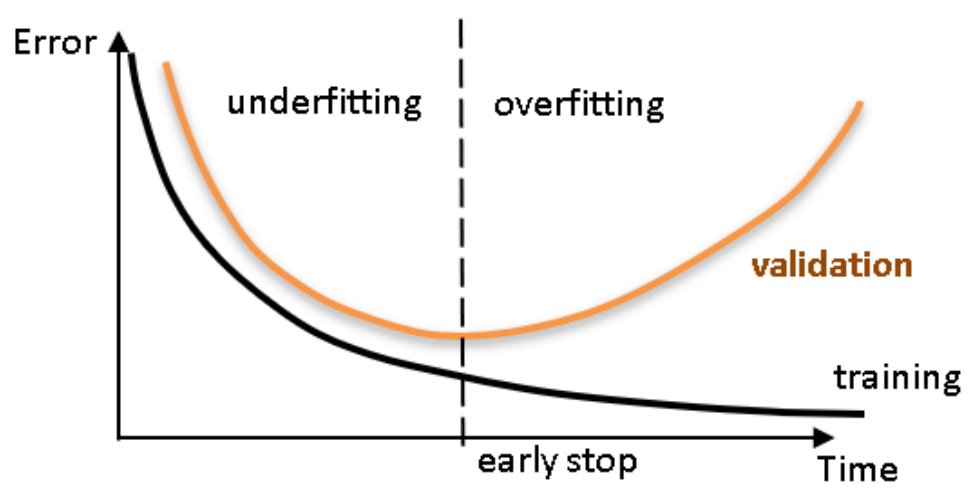

Fig. 3. Assessing ANN's generalization ability via cross-validation.

\subsection{Implemented ANN features}

The mathematical behavior of any ANN depends on many user specifications, having been implemented 15 ANN features in this work (including data pre/post processing ones). For those features, one should bear in mind that the implemented ANNs should not be applied outside the input variable ranges used for network training - they might not give good approximations in extrapolation problems. Since there are no objective rules dictating which method per feature guarantees the best network performance for a specific problem, an extensive parametric analysis (composed of nine parametric sub-analyses) was carried out to find 'the optimum' net design. A description of all methods/formulations implemented for each ANN feature (see Tabs. 2-4) can be found in previous published works (e.g., Abambres et al. 2018, Abambres and He 2018) 
Abambres M, He J (2019). Shear Capacity of Headed Studs in

Steel-Concrete Structures: Analytical Prediction via Soft Computing, hal-02074833

(C) 2019 by Abambres M, He J (CC BY 4.0)

Tab. 2. Adopted ANN features (F) 1-5.

\begin{tabular}{cccccc}
\hline \multirow{2}{*}{$\begin{array}{c}\text { FEATURE } \\
\text { METHOD }\end{array}$} & F1 & F2 & F3 & F4 & F5 \\
\cline { 2 - 6 } & $\begin{array}{c}\text { Qualitative } \\
\text { Var Represent }\end{array}$ & $\begin{array}{c}\text { Dimensional } \\
\text { Analysis }\end{array}$ & $\begin{array}{c}\text { Input Dimensionality } \\
\text { Reduction }\end{array}$ & $\begin{array}{c}\text { \% } \\
\text { Train-Valid-Test }\end{array}$ & $\begin{array}{c}\text { Input } \\
\text { Normalization }\end{array}$ \\
\hline $\mathbf{1}$ & Boolean Vectors & Yes & Linear Correlation & $80-10-10$ & Linear Max Abs \\
$\mathbf{2}$ & Eq Spaced in ]0,1] & No & Auto-Encoder & $70-15-15$ & Linear [0, 1] \\
$\mathbf{3}$ & - & - & - & $60-20-20$ & Linear [-1, 1] \\
$\mathbf{4}$ & - & - & Ortho Rand Proj & $50-25-25$ & Nonlinear \\
$\mathbf{5}$ & - & - & Sparse Rand Proj & - & Lin Mean Std \\
$\mathbf{6}$ & - & - & No & - & No \\
\hline
\end{tabular}

Tab. 3. Adopted ANN features (F) 6-10.

\begin{tabular}{cccccc}
\hline \multirow{2}{*}{$\begin{array}{c}\text { FEATURE } \\
\text { METHOD }\end{array}$} & F6 & F7 & F8 & F9 & F10 \\
\cline { 2 - 5 } & $\begin{array}{c}\text { Output } \\
\text { Transfer }\end{array}$ & $\begin{array}{c}\text { Output } \\
\text { Normalization }\end{array}$ & $\begin{array}{c}\text { Net } \\
\text { Architecture }\end{array}$ & $\begin{array}{c}\text { Hidden } \\
\text { Layers }\end{array}$ & Connectivity \\
\hline $\mathbf{1}$ & Logistic & Lin $[\mathrm{a}, \mathrm{b}]=0.7\left[\varphi_{\min }, \varphi_{\max }\right]$ & MLPN & $1 \mathrm{HL}$ & Adjacent Layers \\
$\mathbf{2}$ & - & Lin $[\mathrm{a}, \mathrm{b}]=0.6\left[\varphi_{\min }, \varphi_{\max }\right]$ & RBFN & $2 \mathrm{HL}$ & Adj Layers + In-Out \\
$\mathbf{3}$ & Hyperbolic Tang & Lin $[\mathrm{a}, \mathrm{b}]=0.5\left[\varphi_{\min }, \varphi_{\max }\right]$ & - & $3 \mathrm{HL}$ & Fully-Connected \\
$\mathbf{4}$ & - & Linear Mean Std & - & - & - \\
$\mathbf{5}$ & Bilinear & No & - & - & - \\
$\mathbf{6}$ & Compet & - & - & - & - \\
$\mathbf{7}$ & Identity & - & - & - & - \\
\hline
\end{tabular}

- the reader might need to go through it to fully understand the meaning of all variables reported in this manuscript. The whole work was coded in MATLAB (The Mathworks, Inc. 2017), making use of its neural network toolbox when dealing with popular learning algorithms (1-3 in Tab. 4). Each parametric sub-analysis (SA) consists of running all feasible combinations (also called 'combos') of pre-selected methods for each ANN feature, in order to get performance results for each designed net, thus allowing the selection of the best ANN according to a certain 
Abambres M, He J (2019). Shear Capacity of Headed Studs in

Steel-Concrete Structures: Analytical Prediction via Soft Computing, hal-02074833

(C) 2019 by Abambres M, He J (CC BY 4.0)

criterion. The best network in each parametric SA is the one exhibiting the smallest average relative error (called performance) for all learning data.

Tab. 4. Adopted ANN features (F) 11-15.

\begin{tabular}{cccccc}
\hline \multirow{2}{*}{$\begin{array}{c}\text { FEATURE } \\
\text { METHOD }\end{array}$} & F11 & F12 & F13 & F14 & F15 \\
\cline { 2 - 6 } & Hidden & $\begin{array}{c}\text { Parameter } \\
\text { Initialization }\end{array}$ & $\begin{array}{c}\text { Learning } \\
\text { Algorithm }\end{array}$ & $\begin{array}{c}\text { Performance } \\
\text { Improvement }\end{array}$ & $\begin{array}{c}\text { Training } \\
\text { Mode }\end{array}$ \\
\hline $\mathbf{1}$ & Logistic & Midpoint $(\mathrm{W})+$ Rands (b) & BP & NNC & Batch \\
$\mathbf{2}$ & Identity-Logistic & Rands & BPA & - & Mini-Batch \\
$\mathbf{3}$ & Hyperbolic Tang & Randnc (W) + Rands (b) & LM & - & Online \\
$\mathbf{4}$ & Bipolar & Randnr (W) + Rands (b) & ELM & - & - \\
$\mathbf{5}$ & Bilinear & Randsmall & mb ELM & - & - \\
$\mathbf{6}$ & Positive Sat Linear & Rand [- $\Delta, \Delta]$ & I-ELM & - & - \\
$\mathbf{7}$ & Sinusoid & SVD & Cl-ELM & - & - \\
$\mathbf{8}$ & Thin-Plate Spline & MB SVD & - & - & - \\
$\mathbf{9}$ & Gaussian & - & - & - & - \\
$\mathbf{1 0}$ & Multiquadratic & - & - & - & - \\
$\mathbf{1 1}$ & Radbas & - & - & - & - \\
\hline
\end{tabular}

\subsection{Network Performance Assessment}

Several types of results were computed to assess network outputs, namely (i) maximum error, (ii) $\%$ errors greater than $3 \%$, and (iii) performance, which are defined next. All abovementioned errors are relative errors (expressed in \%) based on the following definition, concerning a single output variable and data pattern,

$$
e_{q p}=100\left|\frac{d_{q p}-y_{q L p}}{d_{q p}}\right|
$$


Abambres M, He J (2019). Shear Capacity of Headed Studs in

Steel-Concrete Structures: Analytical Prediction via Soft Computing, hal-02074833

(C) 2019 by Abambres M, He J (CC BY 4.0)

where (i) $d_{q p}$ is the $q^{\text {th }}$ desired (or target) output when pattern $p$ within iteration $i\left(p=1, \ldots, P_{i}\right)$ is presented to the network, and (ii) $y_{q L p}$ is net's $q^{\text {th }}$ output for the same data pattern. Moreover, denominator in eq. (1) is replaced by 1 whenever $\left|d_{q p}\right|<0.05-d_{q p}$ in the nominator keeps its real value. This exception to eq. (1) aims to reduce the apparent negative effect of large relative errors associated to target values close to zero. Even so, this trick may still lead to (relatively) large solution errors while groundbreaking results are depicted as regression plots (target vs. predicted outputs).

\subsubsection{Maximum Error}

This variable measures the maximum relative error, as defined by eq. (1), among all output variables and learning patterns.

\subsubsection{Percentage of Errors $>3 \%$}

This variable measures the percentage of relative errors, as defined by eq. (1), among all output variables and learning patterns, that are greater than $3 \%$.

\subsubsection{Performance}

In functional approximation problems, network performance is defined as the average relative error, as defined in eq. (1), among all output variables and data patterns being evaluated (e.g., training, all data). 
Abambres M, He J (2019). Shear Capacity of Headed Studs in

Steel-Concrete Structures: Analytical Prediction via Soft Computing, hal-02074833

(C) 2019 by Abambres M, He J (CC BY 4.0)

\subsection{Parametric Analysis Results}

Aiming to reduce the computing time by cutting in the number of combos to be run - note that all features combined lead to hundreds of millions of combos, the whole parametric simulation was divided into nine parametric SAs, where in each one feature 7 only takes a single value. This measure aims to make the performance ranking of all combos within each 'small' analysis more 'reliable', since results used for comparison are based on target and output datasets as used in ANN training and yielded by the designed network, respectively (they are free of any postprocessing that eliminates output normalization effects on relative error values). Whereas (i) the $1^{\text {st }}$ and $2^{\text {nd }} \mathrm{SAs}$ aimed to select the best methods from features 1, 2, 5, 8 and 13 (all combined), while adopting a single popular method for each of the remaining features $\left(\mathrm{F}_{3}: 6, \mathrm{~F}_{4}: 2, \mathrm{~F}_{6}:\{1\right.$ or 7$\}, \mathrm{F}_{7}: 1, \mathrm{~F}_{9}: 1, \mathrm{~F}_{10}$ : $1, F_{11}:\{3,9$ or 11$\}, F_{12}: 2, F_{14}: 1, F_{15}: 1$ - see Tabs. 2-4) - SA 1 involved learning algorithms 1-3 and SA 2 involved the ELM-based counterpart, (ii) the $3^{\text {rd }}-7^{\text {th }}$ SAs combined all possible methods from features 3, 4, 6 and 7, and concerning all other features, adopted the methods integrating the best combination from the aforementioned SAs 1-2, (iii) the $8^{\text {th }}$ SA combined all possible methods from features 11, 12 and 14, and concerning all other features, adopted the methods integrating the best combination (results compared after postprocessing) among the previous five sub-analyses, and lastly (iv) the $9^{\text {th }}$ SA combined all possible methods from features 9,10 and 15 , and concerning all other features, adopted the methods integrating the best combination from the previous analysis. Summing up the ANN feature combinations for all parametric SAs, a total of 219 combos were run for this work. 
Abambres M, He J (2019). Shear Capacity of Headed Studs in

Steel-Concrete Structures: Analytical Prediction via Soft Computing, hal-02074833

(C) 2019 by Abambres M, He J (CC BY 4.0)

ANN feature methods used in the best combo from each of the abovementioned nine parametric sub-analyses, are specified in Tab. 5 (the numbers represent the method number as in Tabs 2-4). Tab. 6 shows the corresponding relevant results for those combos, namely (i) maximum error, (ii) $\%$ errors $>3 \%$, (iii) performance (all described in section 3, and evaluated for all learning data), (iv) total number of hidden nodes in the model, and (v) average computing time per example (including data pre- and post-processing). All results shown in Tab. 6 are based on target and output datasets computed in their original format, i.e. free of any transformations due to output normalization and/or dimensional analysis. The microprocessors used in this work have the following features: OS: Win10Home 64bits, RAMs: 48/128 GB, Local Disk Memory: 1 TB, CPUs: Intel® Core ${ }^{\mathrm{TM}}$ i7 8700K @ 3.70-4.70 GHz / i9 7960X @ 2.80-4.20 GHz.

Tab. 5. ANN feature (F) methods used in the best combo from each parametric sub-analysis (SA).

\begin{tabular}{cccccccccccccccc}
\hline SA & F1 & F2 & F3 & F4 & F5 & F6 & F7 & F8 & F9 & F10 & F11 & F12 & F13 & F14 & F15 \\
\hline $\mathbf{1}$ & 1 & 2 & 6 & 2 & 2 & 1 & 1 & 1 & 1 & 1 & 3 & 2 & 3 & 1 & 3 \\
$\mathbf{2}$ & 1 & 2 & 6 & 2 & 5 & 7 & 1 & 2 & 1 & 1 & 9 & 2 & 5 & 1 & 3 \\
$\mathbf{3}$ & 1 & 2 & 6 & 2 & 2 & 1 & 1 & 1 & 1 & 1 & 3 & 2 & 3 & 1 & 3 \\
$\mathbf{4}$ & 1 & 2 & 6 & 3 & 2 & 1 & 2 & 1 & 1 & 1 & 3 & 2 & 3 & 1 & 3 \\
$\mathbf{5}$ & 1 & 2 & 6 & 4 & 2 & 1 & 3 & 1 & 1 & 1 & 3 & 2 & 3 & 1 & 3 \\
$\mathbf{6}$ & 1 & 2 & 6 & 4 & 2 & 7 & 4 & 1 & 1 & 1 & 3 & 2 & 3 & 1 & 3 \\
$\mathbf{7}$ & 1 & 2 & 6 & 3 & 2 & 7 & 5 & 1 & 1 & 1 & 3 & 2 & 3 & 1 & 3 \\
$\mathbf{8}$ & 1 & 2 & 6 & 3 & 2 & 7 & 5 & 1 & 1 & 1 & 1 & 5 & 3 & 1 & 3 \\
$\mathbf{9}$ & 1 & 2 & 6 & 3 & 2 & 7 & 5 & 1 & 3 & 3 & 1 & 5 & 3 & 1 & 3 \\
\hline
\end{tabular}


Abambres M, He J (2019). Shear Capacity of Headed Studs in

Steel-Concrete Structures: Analytical Prediction via Soft Computing, hal-02074833

(C) 2019 by Abambres M, He J (CC BY 4.0)

Tab. 6. Performance results for the best design from each parametric sub-analysis: (a) ANN, (b) NNC.

\begin{tabular}{cccccc}
\hline SA & \multicolumn{5}{c}{ ANN } \\
\cline { 2 - 6 } & $\begin{array}{c}\text { Max Error } \\
(\%)\end{array}$ & $\begin{array}{c}\text { Performance } \\
\text { All Data } \\
(\%)\end{array}$ & $\begin{array}{c}\text { Errors }>3 \% \\
(\%)\end{array}$ & $\begin{array}{c}\text { Total Hidden } \\
\text { Nodes }\end{array}$ & $\begin{array}{c}\text { Running Time / } \\
\text { Data Point } \\
(\text { (s) })\end{array}$ \\
\hline $\mathbf{1}$ & 5.4 & 1.1 & 5.6 & 12 & $6.71 \mathrm{E}-05$ \\
$\mathbf{2}$ & 48.5 & 1.7 & 14.5 & 110 & $7.27 \mathrm{E}-05$ \\
$\mathbf{3}$ & 4.2 & 1.1 & 3.8 & 12 & $5.79 \mathrm{E}-05$ \\
$\mathbf{4}$ & 6.5 & 1.1 & 3.8 & 12 & $5.51 \mathrm{E}-05$ \\
$\mathbf{5}$ & 7.7 & 1.1 & 5.6 & 12 & $5.23 \mathrm{E}-05$ \\
$\mathbf{6}$ & 9.3 & 1.2 & 8.1 & 12 & $6.25 \mathrm{E}-05$ \\
$\mathbf{7}$ & 8.8 & 1.3 & 7.7 & 12 & $9.17 \mathrm{E}-05$ \\
$\mathbf{8}$ & 5.8 & 1.2 & 8.1 & 12 & $7.70 \mathrm{E}-05$ \\
$\mathbf{9}$ & 3.3 & 0.6 & 0.4 & 12 & $5.64 \mathrm{E}-05$ \\
\hline
\end{tabular}

(a)

\begin{tabular}{cccccc}
\hline SA & \multicolumn{5}{c}{ NNC } \\
\cline { 2 - 6 } & $\begin{array}{c}\text { Max Error } \\
(\%)\end{array}$ & $\begin{array}{c}\text { Performance } \\
\text { All Data } \\
(\%)\end{array}$ & $\begin{array}{c}\text { Errors }>3 \% \\
(\%)\end{array}$ & $\begin{array}{c}\text { Total Hidden } \\
\text { Nodes }\end{array}$ & $\begin{array}{c}\text { Running Time / } \\
\text { Data Point } \\
(\mathbf{\%})\end{array}$ \\
\hline $\mathbf{1}$ & - & - & - & - & - \\
$\mathbf{2}$ & - & - & - & - & - \\
$\mathbf{3}$ & - & - & - & - & - \\
$\mathbf{4}$ & - & - & - & - & - \\
$\mathbf{5}$ & - & - & - & - & - \\
$\mathbf{6}$ & 6.7 & 0.9 & 3.8 & 12 & $7.54 \mathrm{E}-05$ \\
$\mathbf{7}$ & 2.6 & 0.6 & 0.0 & 12 & $9.67 \mathrm{E}-05$ \\
$\mathbf{8}$ & 2.5 & 0.3 & 0.0 & 12 & $8.78 \mathrm{E}-05$ \\
$\mathbf{9}$ & - & - & - & - & - \\
\hline
\end{tabular}

(b)

\subsection{Proposed ANN-Based Model}

The proposed model is the one, among the best ones from all parametric SAs, exhibiting the lowest maximum error (SA 9). That model is characterized by the ANN feature methods $\{1,2,6$, $3,2,7,5,1,3,3,1,5,3,1,3\}$ in Tabs. 2-4. Aiming to allow implementation of this model by any user, all variables/equations required for (i) data preprocessing, (ii) ANN simulation, and (iii) data postprocessing, are presented in 3.6.1-3.6.3, respectively. The proposed model is a single MLPN with 5 layers and a distribution of nodes/layer of 3-4-4-4-1. Concerning connectivity, the network 
Abambres M, He J (2019). Shear Capacity of Headed Studs in

Steel-Concrete Structures: Analytical Prediction via Soft Computing, hal-02074833

(C) 2019 by Abambres M, He J (CC BY 4.0)

is fully-connected, and the hidden and output transfer functions are all Logistic and Identity, respectively. The network was trained using the Levenberg-Marquardt algorithm (1500 epochs). After design, the average network computing time concerning the presentation of a single example (including data pre/postprocessing) is $5.64 \times 10^{-5} \mathrm{~s}-$ Fig. 4 depicts a simplified scheme of some of network key features. Lastly, all relevant performance results concerning the proposed ANN are illustrated in 3.6.4. The obtained ANN solution for every data point can be found in Developer (2018a).

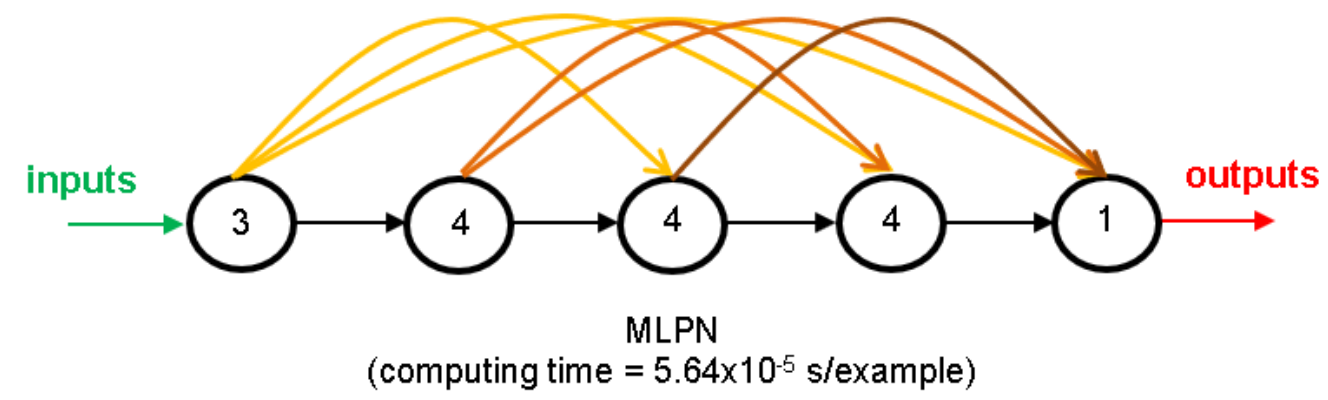

Fig. 4 Proposed 3-4-4-4-1 fully-connected MLPN - simplified scheme.

It is worth recalling that, in this manuscript, whenever a vector is added to a matrix, it means the former is to be added to all columns of the latter (valid in MATLAB).

\subsubsection{Input Data Preprocessing}

For future use of the proposed ANN to simulate new data $Y_{1, \operatorname{sim}}\left(3 \times P_{\text {sim }}\right.$ matrix), concerning $P_{\text {sim }}$ patterns, the same data preprocessing (if any) performed before training must be applied to the input dataset. That preprocessing is defined by the methods used for ANN features 2, 3 
Abambres M, He J (2019). Shear Capacity of Headed Studs in

Steel-Concrete Structures: Analytical Prediction via Soft Computing, hal-02074833

(C) 2019 by Abambres M, He J (CC BY 4.0)

and 5 (respectively 2, 6 and 2 - see Tab. 2). Next, the necessary preprocessing to be applied to $Y_{1, \text { sim }}$, concerning features 2,3 and 5 , is fully described.

\section{Dimensional Analysis and Dimensionality Reduction}

Since no dimensional analysis (d.a.) nor dimensionality reduction (d.r.) were carried out, one has

$$
\left\{Y_{1, \text { sim }}\right\}_{\text {d.r. }}^{\text {after }}=\left\{Y_{1, \text { sim }}\right\}_{\text {d.a. }}^{\text {after }}=Y_{1, \text { sim }}
$$

\section{Input Normalization}

After input normalization, the new input dataset $\left\{Y_{1, \text { sim }}\right\}_{n}^{\text {after }}$ is defined as function of the previously determined $\left\{Y_{1, \text { sim }}\right\}_{d . r}^{\text {after }}$, and they have the same size, reading

$$
\begin{aligned}
& \left\{Y_{1, \text { sim }}\right\}_{n}^{\text {after }}=\operatorname{INP}(:, 1)+\text { rab.x }\left(\left\{Y_{1, \text { sim }}\right\}_{d . r}^{\text {after }}-\operatorname{INP}(:, 3)\right) \cdot / \text { den } \\
& \operatorname{INP}=\left[\begin{array}{cccc}
0 & 1 & 9.5 & 30 \\
0 & 1 & 18.3 & 109.3 \\
0 & 1 & 305.7 & 595
\end{array}\right] \\
& r a b=\operatorname{INP}(:, 2)-\operatorname{INP}(:, 1) \\
& \text { den }=\operatorname{INP}(:, 4)-\operatorname{INP}(:, 3)
\end{aligned}
$$

where one recalls that operator '. $\mathrm{x}$ ' multiplies component $i$ in vector $r a b$ by all components in row $i$ of subsequent term (analogous definition holds for '.l'). 
Abambres M, He J (2019). Shear Capacity of Headed Studs in

Steel-Concrete Structures: Analytical Prediction via Soft Computing, hal-02074833

(C) 2019 by Abambres M, He J (CC BY 4.0)

\subsubsection{ANN-Based Analytical Model}

Once determined the preprocessed input dataset $\left\{Y_{1, \text { sim }}\right\}_{n}{ }^{\text {after }}\left(3 \times P_{\text {sim }}\right.$ matrix $)$, the next step is to present it to the proposed ANN to obtain the predicted output dataset $\left\{Y_{5, \text { sim }}\right\}_{n}^{\text {after }}$ (1 $\mathrm{x} P_{\text {sim }}$ vector), which will be given in the same preprocessed format of the target dataset used in learning. In order to convert the predicted outputs to their 'original format' (i.e., without any transformation due to normalization or dimensional analysis), some postprocessing is needed, as described in detail in 3.6.3. Next, the mathematical representation of the proposed ANN is given, so that any user can implement it to determine $\left\{Y_{5, \text { sim }}\right\}_{n}$ after , thus eliminating all rumors that ANNs are 'black boxes'.

$$
\begin{aligned}
& Y_{2}=\varphi_{2}\left(W_{1-2}^{T}\left\{Y_{1, \text { sim }}\right\}_{n}^{\text {after }}+b_{2}\right) \\
& Y_{3}=\varphi_{3}\left(W_{1-3}^{T}\left\{Y_{1, \text { sim }}\right\}_{n}^{\text {after }}+W_{2-3}^{T} Y_{2}+b_{3}\right) \\
& Y_{4}=\varphi_{4}\left(W_{1-4}^{T}\left\{Y_{1, \text { sim }}\right\}_{n}^{\text {after }}+W_{2-4}^{T} Y_{2}+W_{3-4}^{T} Y_{3}+b_{4}\right) \\
& \left\{Y_{5, \text { sim }}\right\}_{n}^{\text {after }}=\varphi_{5}\left(W_{1-5}^{T}\left\{Y_{1, \text { sim }}\right\}_{n}^{\text {after }}+W_{2-5}^{T} Y_{2}+W_{3-5}^{T} Y_{3}+W_{4-5}^{T} Y_{4}+b_{5}\right)
\end{aligned}
$$

where

$$
\begin{aligned}
& \varphi_{2}=\varphi_{3}=\varphi_{4}=\varphi(s)=\frac{1}{1+e^{-s}} \\
& \varphi_{5}=\varphi_{5}(s)=s
\end{aligned}
$$

Arrays $W_{j-s}$ and $b_{s}$ are stored online in Developer (2018b), aiming to avoid an overlong article and ease model's implementation by any interested reader. 
Abambres M, He J (2019). Shear Capacity of Headed Studs in

Steel-Concrete Structures: Analytical Prediction via Soft Computing, hal-02074833

(C) 2019 by Abambres M, He J (CC BY 4.0)

\subsubsection{Output Data Postprocessing}

In order to transform the output dataset obtained by the proposed $A N N,\left\{Y_{5, s i m}\right\}_{n}{ }^{\text {after }}(1 \mathrm{x}$ $P_{\text {sim }}$ vector $)$, to its original format $\left(Y_{5, \operatorname{sim}}\right)$, i.e. without the effects of dimensional analysis and/or output normalization (possibly) taken in target dataset preprocessing prior training, one has

$$
Y_{5, \text { sim }}=\left\{Y_{5, \text { sim }}\right\}_{\text {d.a. }}^{\text {after }}=\left\{Y_{5, \text { sim }}\right\}_{n}^{\text {after }}
$$

since no output normalization nor dimensional analysis were carried out.

\subsubsection{Performance Results}

Finally, results yielded by the proposed ANN, in terms of performance variables defined in sub-section 3.4, are presented in this section in the form of several graphs: (i) a regression plot (Fig. 5) where network target and output data are plotted, for each data point, as $x$ - and $y$ coordinates respectively - a measure of linear correlation is given by the Pearson Correlation Coefficient $(R)$; (ii) a performance plot (Fig. 6), where performance (average error) values are displayed for several learning datasets; and (iii) an error plot (Fig. 7), where values concern all data (iii 1 ) maximum error and ( $\left.\mathrm{iii}_{2}\right) \%$ of errors greater than $3 \%$. 
Abambres M, He J (2019). Shear Capacity of Headed Studs in

Steel-Concrete Structures: Analytical Prediction via Soft Computing, hal-02074833

(C) 2019 by Abambres M, He J (CC BY 4.0)

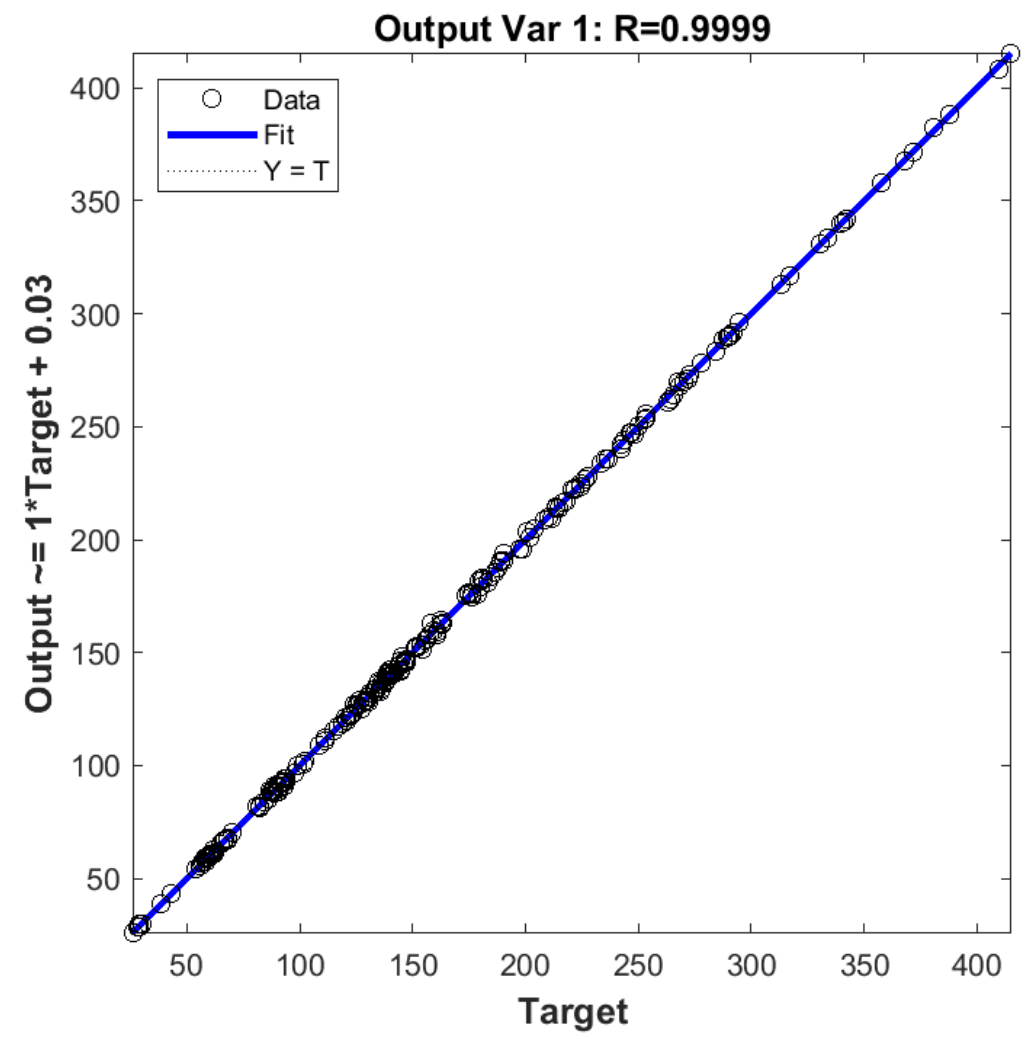

Fig. 5. Regression plot for the proposed ANN.

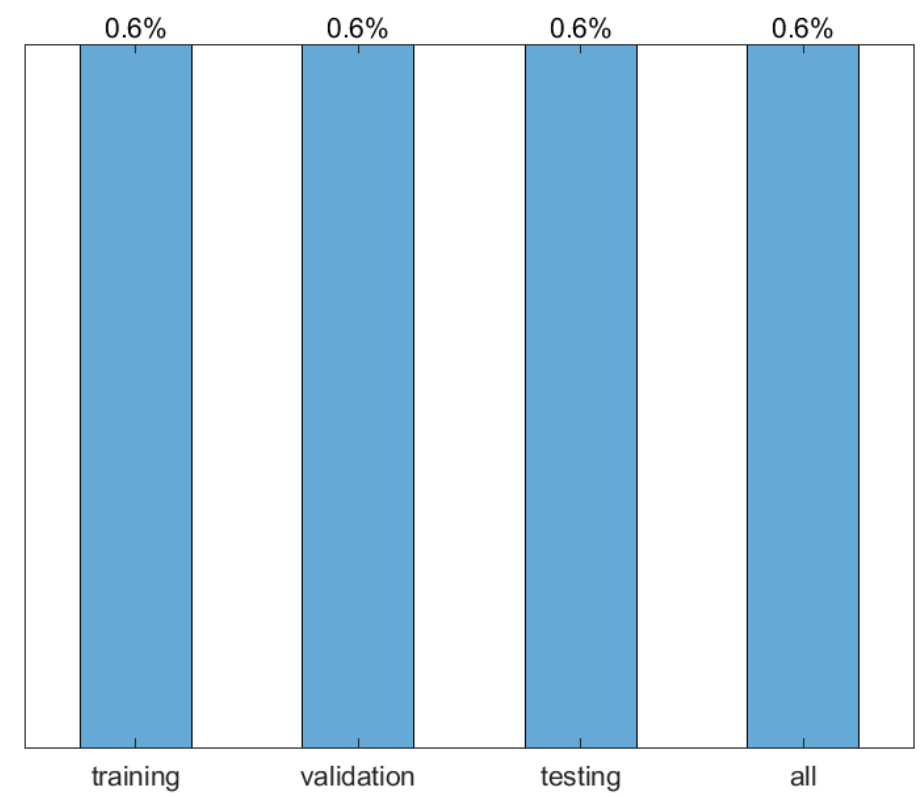

Fig. 6. Performance plot (mean errors) for the proposed ANN. 
Abambres M, He J (2019). Shear Capacity of Headed Studs in

Steel-Concrete Structures: Analytical Prediction via Soft Computing, hal-02074833

(C) 2019 by Abambres M, He J (CC BY 4.0)

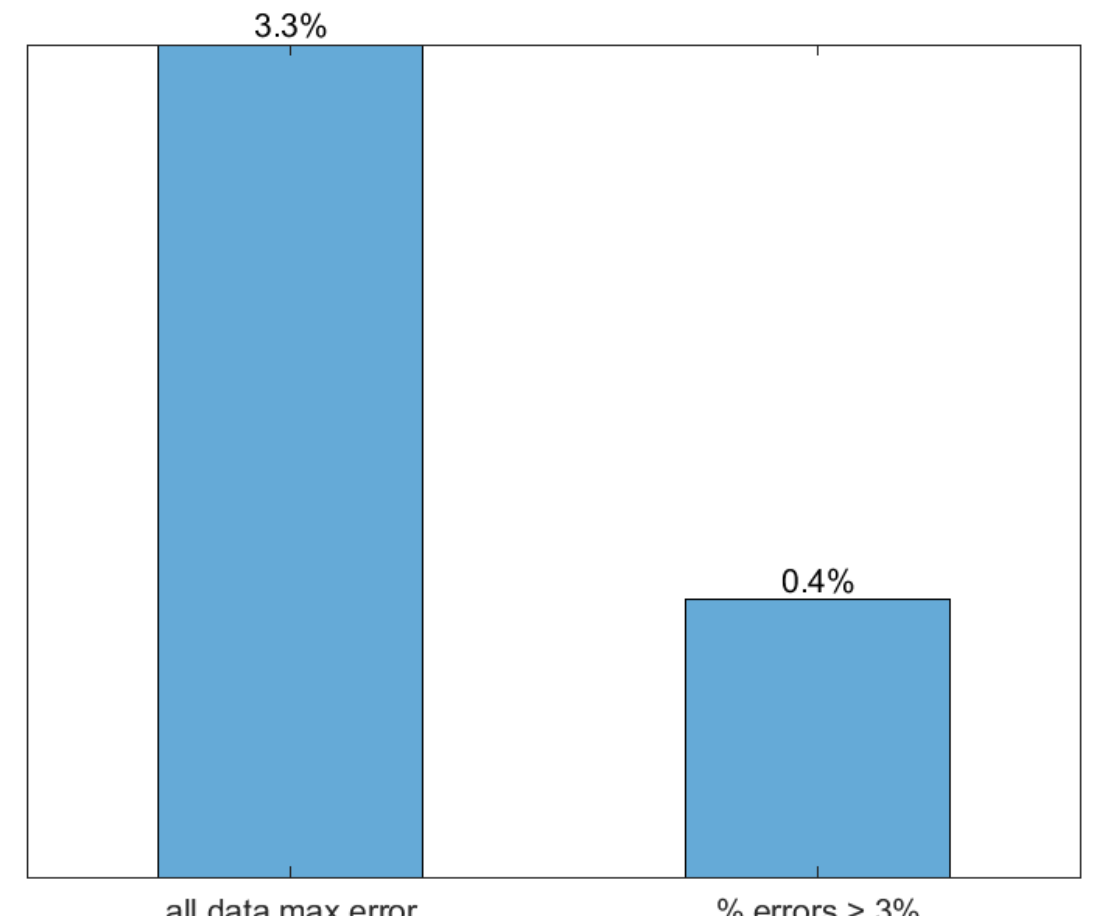

all data max error

$\%$ errors $>3 \%$

Fig. 7. Error plot for the proposed ANN.

\section{ANN-based vs. Existing Code-based Models}

The shear capacity of headed steel studs depends on many factors, including the material and diameter of the stud and properties of the surrounding concrete slab. These factors are all included in several design codes. The collected test results and ANN predictions have been used to assess the design equations given by Eurocode 4 (CEN 2005b), AASHTO (2014), and GB50017 (MC-PRC and GAQSIQ-PRC 2003).

In AASHTO (2014), the shear strength $\left(P_{\mathrm{u}}\right)$ of one stud shear connector embedded in a reinforced concrete deck can be calculated by

$$
P_{u}=\phi_{s c} 0.5 A_{s} \sqrt{E_{c} f_{c}^{\prime}} \leq \phi_{s c} A_{s} f_{u}
$$


Abambres M, He J (2019). Shear Capacity of Headed Studs in

Steel-Concrete Structures: Analytical Prediction via Soft Computing, hal-02074833

(C) 2019 by Abambres M, He J (CC BY 4.0)

where (i) $A_{s}$ is the stud shank cross-sectional area, (ii) $f_{c}{ }^{\prime}$ is the cylinder-based compressive strength of concrete, (iii) $f_{u}$ is the tensile strength of the stud steel, (iv) $E_{c}$ is the concrete Young's modulus, and (v) $\phi_{\mathrm{sc}}=0.85$ is the resistance safety factor.

As provided in Eurocode 4 (CEN 2005b), the stud shear strength $\left(P_{\mathrm{u}}\right)$ is determined by

$$
P_{u}=0.29 \alpha d^{2} \sqrt{E_{c} f_{c}^{\prime}} / \gamma_{v} \leq 0.8 A_{s} f_{u} / \gamma_{v}
$$

where (i) $d$ is the stud shank diameter, (ii) $\gamma_{v}=1.25$ is the material safety factor, (iii) $\alpha$ is the aspect ratio factor given by

$$
\begin{array}{ll}
\alpha=0.2\left(\frac{h_{s c}}{d}+1\right), & \text { if } \quad 3 \leq \frac{h_{s c}}{d} \leq 4 \\
\alpha=1.0 \quad, \text { if } \quad \frac{h_{s c}}{d}>4
\end{array}
$$

being $h_{s c}$ the length of the stud shank (the remaining variables have been previously defined).

The Chinese Code GB50017 (MC-PRC and GAQSIQ-PRC 2003) requires the design shear strength of a headed stud $\left(P_{\mathrm{u}}\right)$ to be computed as

$$
P_{u}=0.43 A_{s} \sqrt{E_{c} f_{c}} \leq 0.7 \gamma A_{s} f_{u}
$$

where $f_{c}$ is the cube-based compressive strength of concrete, and $\gamma \geq 1.25$ is the ratio of the minimum tensile strength to the yield stress of the stud steel (the remaining variables have been previously defined).

Fig.8 compares the shear capacity of headed steel studs as yielded by the aforementioned code-based models $\left(P_{u_{-} c o d e}\right)$ to those obtained experimentally $\left(P_{u_{-} \exp }\right)$, concerning the 234 pushout test results collected for this work (test- and ANN-based results available in Developer 
Abambres M, He J (2019). Shear Capacity of Headed Studs in

Steel-Concrete Structures: Analytical Prediction via Soft Computing, hal-02074833

(C) 2019 by Abambres M, He J (CC BY 4.0)

2018a). The average ratios $P_{u_{-} \text {code }} / P_{u_{-} \text {exp }}$ for codes AASHTO, Eurocode 4 and GB50017 are $0.84,0.63$ and 0.87 , with standard deviations of $0.03,0.02$ and 0.02 , respectively. It can be found that all those design models underestimate the shear capacity of the stud connector. For comparison, the average ratio $P_{u_{-} A N N} / P_{u_{-} \exp }$ for the proposed ANN is 1.00 , with a standard deviation of 0.009 . The major improvement of the proposed ANN-based analytical model (see sub-section 3.6), as compared to the existing code-based equations, becomes quite clear in Fig. 8, where the predicted and experimental shear capacities are represented by the $\mathrm{x}$ - and $\mathrm{y}$-axis, respectively.

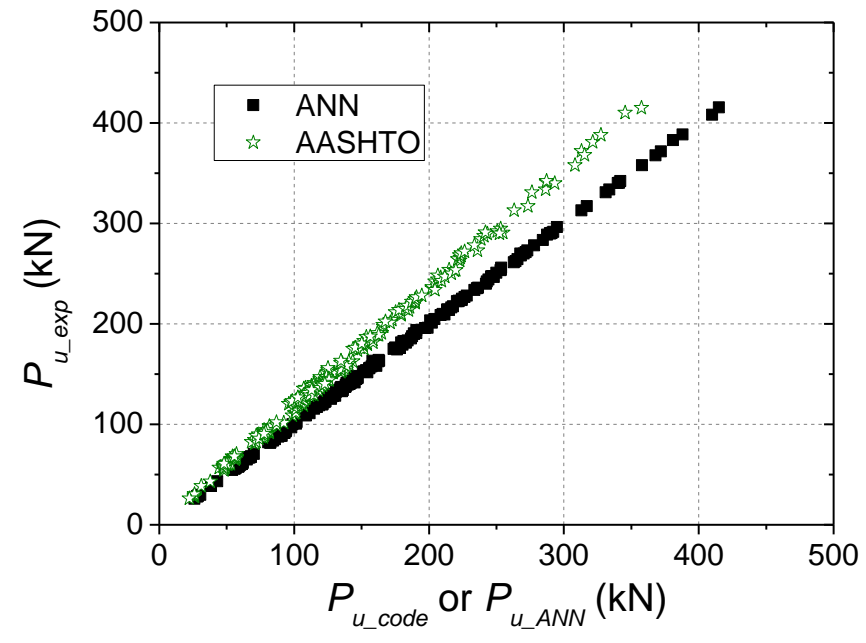


Abambres M, He J (2019). Shear Capacity of Headed Studs in

Steel-Concrete Structures: Analytical Prediction via Soft Computing, hal-02074833

(C) 2019 by Abambres M, He J (CC BY 4.0)
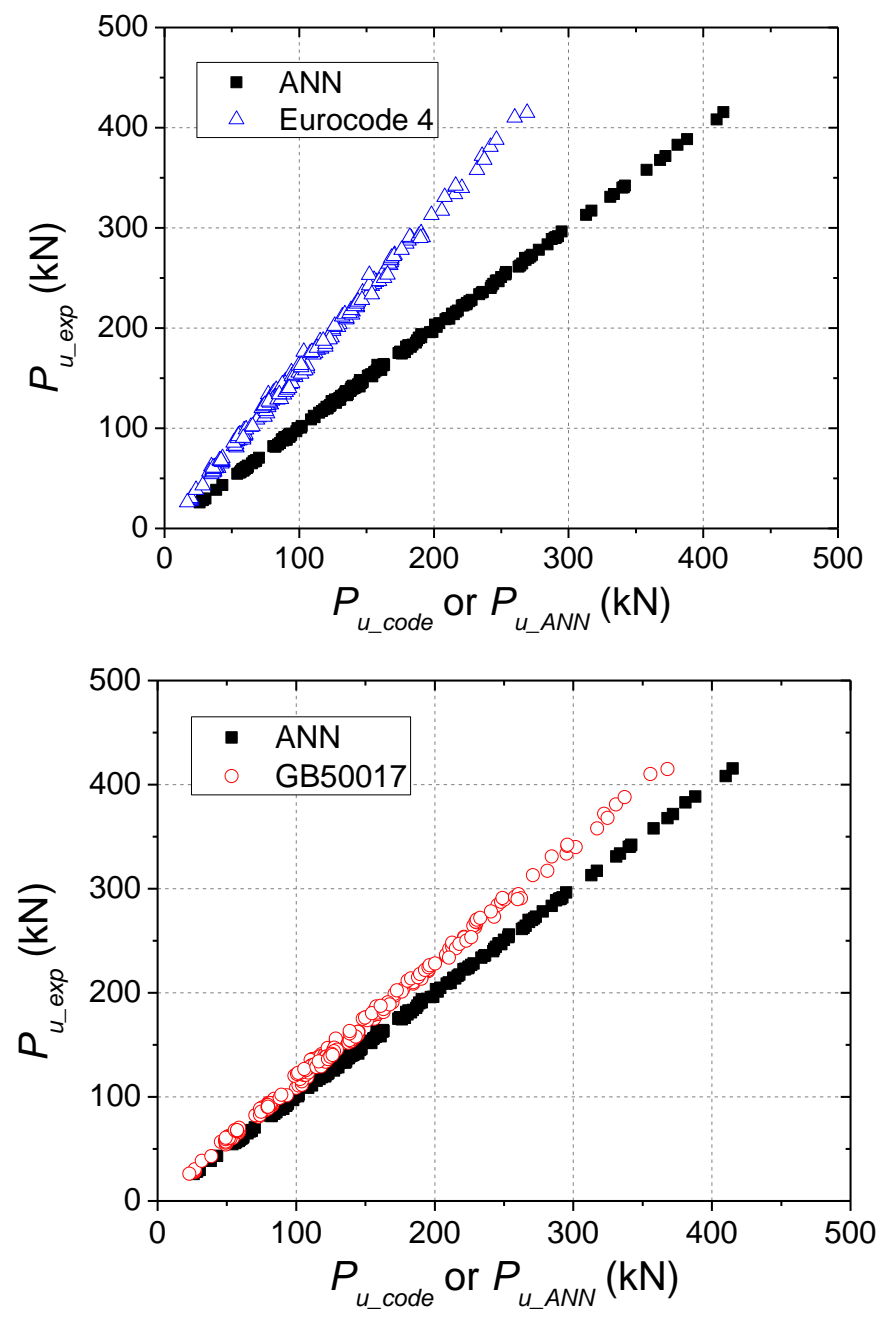

Fig. 8. Comparison between and predicted shear capacities for 234 headed steel studs.

\section{Discussion}

Regardless the high quality of the predictions yielded by the proposed model, the reader should not blindly accept it as accurate for any other instances falling inside the input domain of the design dataset. Any analytical approximation model must undergo extensive validation before it can be taken as reliable (the more inputs, the larger the validation process). Models proposed meanwhile are part of a learning process towards excellence. 
Abambres M, He J (2019). Shear Capacity of Headed Studs in

Steel-Concrete Structures: Analytical Prediction via Soft Computing, hal-02074833

(C) 2019 by Abambres M, He J (CC BY 4.0)

\section{Conclusions}

This paper describes how artificial neural networks (ANN) can be used to predict the shear capacity of headed steel stud connectors in steel-concrete structures. It proposes an analytical model for that purpose, designed from a 234-point database of push-out test results available in the literature. Three governing (geometrical and material) parameters were identified as input variables, and the shear force at failure was considered as the target/output variable for the ANN simulations. The proposed ANN-based analytical model yielded maximum and mean relative errors of $3.3 \%$ and $0.6 \%$ concerning all the 234 push-out test results previously collected. Fig. 8 shows that the ANN-based approach clearly outperforms the existing codebased equations assessed in this work, for the data used (made available at Developer 2018a) - latter models exhibit mean errors greater than $13 \%$.

The focus of this study was not to assess the mechanics underlying the behaviour of headed studs, but parametric studies by means of accurate and robust ANN-based models make it possible to evaluate and improve existing mechanical models.

\section{Contributions}

He J. developed sections 1, 2 and 4; Abambres M. developed sections 3 and 5 (ANNrelated); Remaining sections had equal contributions from both authors.

\section{References}

Abambres M, He J (2018). Neural network-based analytical model to predict the shear strength of steel girders with a trapezoidal corrugated web, hal-02074778

Abambres M, Rajana K, Tsavdaridis K, Ribeiro T (2018). Neural Network-based formula for the buckling load prediction of I-section cellular steel beams, hal-02074835 
Abambres M, He J (2019). Shear Capacity of Headed Studs in

Steel-Concrete Structures: Analytical Prediction via Soft Computing, hal-02074833

(C) 2019 by Abambres M, He J (CC BY 4.0)

American Association of State Highway and Transportation Officials (AASHTO) (2014). AASHTO LRFD bridge design specifications. AASHTO, Washington DC, USA.

American Institute for Steel Construction (AISC) (1961). Specification for the design, fabrication and erection of structural steel buildings. AISC, New York, USA.

American Institute for Steel Construction (AISC) (1978). Specification for the design, fabrication and erection of structural steel buildings. AISC, Chicago (IL), USA.

American Institute for Steel Construction (AISC) (1993). Load and resistance factor design specification for structural steel buildings. AISC, Chicago (IL), USA.

An L, Cederwall K (1996). Push-out tests on studs in high strength and normal strength concrete. J. Constr. Steel Res, 36(1), 15-29.

Badie SS, Tadros MK, Kakish HF (2002). Large shear studs for composite action in steel bridge girders. J. Bridg. Eng, 7(3), 195-203.

Bijlaard FSK, Sedlacek G, Stark JWB (1988). Procedure for the Determination of Design Resistance From Tests. Report BI-87-112E, TNO Building and Construction Research, Delft, The Netherlands.

British Standard Institution (BSI) (1978). Steel, Concrete and Composite Bridges, Part 3: Code of Practice for Design of Steel Bridges. BS5400, British Standard Institution, London, UK.

British Standard Institution (BSI) (1979). Steel, concrete and composite bridges. Part 5: Code of practice for design of composite bridges. BS5400, British Standard Institution, London, UK.

Chinn J (1965). Push out Tests on Lightweight Composite Slabs. Engineering Journal (AISC), 2(4), 129-34.

Colajanni P, La Mendola L, Monaco A (2014). Stress transfer mechanism investigation in hybrid steel trussed-concrete beams by push-out tests. J Constr Steel Res, 95(April), 56-70.

Comite Européen de Normalisation (CEN) (1998): Eurocode 3: Design of steel structures - Part 1-1: General rules and rules for buildings. ENV 1993-1-1:1992+A2, Annexes G, H, J (revised), N and Z, Brussels, Belgium.

Comite Européen de Normalisation (CEN) (2004a). Eurocode 2: Design of concrete structures - Part 1-1: General rules and rules for buildings. EN 1992-1-1, Brussels, Belgium.

Comite Européen de Normalisation (CEN) (2004b). Eurocode 4: Design of Composite Steel and Concrete Structures - Part 1-1: General Rules and Rules for Buildings. EN 1994-1-1, Brussels, Belgium.

Comite Européen de Normalisation (CEN) (2005a). Eurocode: Basis of structural design. EN 1990: 2002+A1, Brussels, Belgium.

Comite Européen de Normalisation (CEN) (2005b): Eurocode 4: Design of Composite Steel and Concrete Structures - Part 2: General Rules and Rules for Bridges. EN 1994-2, Brussels, Belgium. 
Abambres M, He J (2019). Shear Capacity of Headed Studs in

Steel-Concrete Structures: Analytical Prediction via Soft Computing, hal-02074833

(C) 2019 by Abambres M, He J (CC BY 4.0)

Commission of the European Communities (CEC) (1984). Eurocode no. 2: Common Unified Rules for Concrete Structures. Report EUR 8848, Commission of the European Communities, Brussels, Belgium.

Commission of the European Communities (CEC) (1985). Eurocode no. 4: Common Unified Rules for Composite Steel and Concrete Structures. Report EUR 9886, Commission of the European Communities, Brussels, Belgium.

Davies C (1967). Small-scale push-out tests on welded stud shear connectors. Concrete, 1(9), 311-316.

Developer (2018a). dataset + results [Data set], downloadable

Developer (2018b). W and b arrays [Data set], downloadable

Dogan O, Roberts TM (2012). Fatigue performance and stiffness variation of stud connectors in steelconcrete-steel sandwich systems. J. Constr. Steel Res, 70(March), 86-92.

Driscoll GC, Slutter RG (1961). Research on composite design at Lehigh University. Proceedings of the Thirteenth National Engineering Conference of AISC, Minneapolis, USA, May 11, 18-24.

Flood I (2008). Towards the next generation of artificial neural networks for civil engineering, Advanced Engineering Informatics, 22(1), 4-14.

Gattesco N, Giuriani E (1996). Experimental study on stud shear connectors subjected to cyclic loading. J. Constr. Steel Res, 38(1), 1-21.

Han Q, Wang Y, Xu J, Xing Y (2015). Static behavior of stud shear connectors in elastic concrete-steel composite beams. J Constr Steel Res, 113(October), 115-26.

Han QH, Wang YH, Xu J, Xing Y (2017). Numerical analysis on shear stud in push-out test with crumb rubber concrete. J. Constr. Steel Res., 130(March), 148-158.

Hawkins NM (1973). The strength of stud shear connectors. Civil Engineering Transactions, Vol. CE15, 46-52.

Haykin SS (2009). Neural networks and learning machines, Prentice Hall/Pearson, New York, USA.

He J, Liu Y, Chen A, Yoda T (2010). Experimental study on inelastic mechanical behaviour of composite girders under hogging moment. Journal of Constructional Steel Research, 66(1), 37-52.

He J, Liu Y, Pei B (2014). Experimental study of the steel-concrete connection in hybrid cable-stayed bridges. J Perform Constr Facil, 28(3), 559-70.

Hern A (2016). Google says machine learning is the future. So I tried it myself. Available at URL [Accessed: 2 November 2016].

Hertzmann A, Fleet D (2012). Machine Learning and Data Mining, Lecture Notes CSC 411/D11, Computer Science Department, University of Toronto, Canada.

Hiragi H, Matsui S, Sato T (2003). Pull-out and shear strength equations for headed studs considering edge distance. Structural Engineering/Earthquake Engineering, 20(1), 69-80.

Johnson RP, Greenwood RD, Van Dalen K (1969). Stud shear connectors in hogging moment regions of composite beams. Struct. Eng, 47(9), 345-350. 
Abambres M, He J (2019). Shear Capacity of Headed Studs in

Steel-Concrete Structures: Analytical Prediction via Soft Computing, hal-02074833

(C) 2019 by Abambres M, He J (CC BY 4.0)

Kim JS, Kwark J, Joh C (2015). Headed stud shear connector for thin ultrahigh performance concrete bridge deck. J. Constr. Steel Res, 108(May), 23-30.

Lam D, El-Lobody E (2005). Behavior of headed stud shear connectors in composite beam. J Struct Eng, 131(1), 96-107.

Lee PG, Shim CS, Chang SP (2005). Static and fatigue behavior of large stud shear connectors for steelconcrete composite bridges. J. Constr. Steel Res, 61(9), 1270-1285.

Lin W, Yoda T, Taniguchi N, Kasano H, He J (2014). Mechanical Performance of Steel-Concrete Composite Beams Subjected to a Hogging Moment. Journal of Structural Engineering, 140(1), 111.

Lin Z, Liu Y, He J (2014). Behavior of stud connectors under combined shear and tension loads. Engineering Structures, 81(December), 362-376.

Mahmood MT, Poi NS, Cher ST (2009). Push-off tests on pin-connected shear studs with composite steel-concrete beams. Constr. Build. Mater, 23(9), 3024-3033.

Mainstone RJ, Menzies JB (1967). Shear connectors in steel-concrete composite beams for bridges. Concrete, 1(9), 291-302.

Marko P, Zlatko M, Milan V, Budevac D (2013). Bolted shear connectors vs. headed studs behavior in push-out tests. J Constr Steel Res, 88(September), 134-149.

McCulloch WS, Pitts W (1943). A logical calculus of the ideas immanent in nervous activity. Bulletin of Mathematical Biophysics, 5(4), 115-133.

Menzies JB (1971). CP 117 and shear connectors in steel-concrete composite beams made with normaldensity or lightweight concrete. Structural Engineer, 49(3), 137-154.

Newmark NM, Siess CP, Viest IM (1951). Tests and analyses of composite beams with incomplete interaction. Society for Experimental Stress Analysis, 9(1), 75-92.

Nguyen HT, Kim SE (2009). Finite element modeling of push-out tests for large stud shear connectors. J Constr Steel Res , 65(10-11), 1909-20.

Oehler DJ, Johnson RP (1987). The strength of stud shear connections in composite beams. The Structural Engineer, 65B(2), 44-48.

Oehlers DJ (1989). Splitting induced by shear connectors in composite beams. J Struct Eng, 115(2), 341-62.

Oehlers DJ, Bradford MA (1995). Composite steel and concrete structural members: Fundamental behavior, Pergamon, Oxford, UK.

Oehlers DJ, Bradford MA (1999). Elementary behavior of composite steel and concrete structural members. Taylor \& Francis, UK, ISBN 978-0-7506-3269-0

Oehlers DJ, Coughlan CG (1986). The shear stiffness of stud shear connections in composite beams. Journal of Constructional Steel Research, 6(4), 273-84.

Ollgaard J, Slutter RG, Fisher J W (1971). Shear strength of stud connectors in lightweight and normal - weight concrete. Engineering Journal of American Institute of Steel Construction, 8(2), 55-64 
Abambres M, He J (2019). Shear Capacity of Headed Studs in

Steel-Concrete Structures: Analytical Prediction via Soft Computing, hal-02074833

(C) 2019 by Abambres M, He J (CC BY 4.0)

Pallarés L, Hajjar JF (2010). Headed steel stud anchors in composite structures, Part I: Shear. J. Constr. Steel Res, 66(2), 198-212.

Prieto A, Prieto B, Ortigosa EM, Ros E, Pelayo F, Ortega J, Rojas I (2016). Neural networks: An overview of early research, current frameworks and new challenges, Neurocomputing, 214(November), 242-268.

Roik K, Hanswille G, Cunze-O Lanna A (1989). Harmonisation of the European Construction Codes Eurocode 2, 4 and 8/Part 3 - Report on Eurocode 4 Clause 6.3.2: Stud Connectors, Institut für Konstruktiven Ingenieurbau, Ruhr-Universitat-Bochum, Germany.

Roš M (1934). Les constructions acier-béton système «Alpha». L'Ossature Métallique, 3(4), 195-208.

Shanmugam N, Lakshmi B (2001). State of the art report on steel-concrete composite columns. J Constr Steel Res, 57(10), 1041-80.

Shim CS, Lee PG, Yoon TY (2004). Static behavior of large stud shear connectors. Eng. Struct, 26(12), 1853-1860.

Slutter, RG, Driscoll, GC (1965). Flexural strength of steel-concrete composite beams. Journal of the Structural Division (ASCE), 91(ST2), 71-99.

Steele DH (1967). The use of nelson studs with lightweight aggregate concrete in composite construction. MSc thesis, University of Colorado, Boulder (CO), USA.

The Mathworks, Inc (2017). MATLAB R2017a, User's Guide, Natick, USA.

The Ministry of Construction of the People's Republic of China (MC-PRC), The General Administration of Quality Supervision, Inspection and Quarantine of the People's Republic of China (GAQSIQ-PRC) (2003). Code for design of steel structures. GB50017, MC-PRC and GAQSIQPRC, Beijing, China.

Thturlimann B (1959). Fatigue and static strength of stud shear connectors. Journal Proceedings, 55(6), 1287-1302.

Topkaya C, Yura JA, Williamson EB (2004). Composite shear stud strength at early concrete ages. Journal of Structural Division (ASCE), 130(6), 952-60.

Valente IB, Cruz PJS (2009). Experimental analysis of shear connection between steel and lightweight concrete. J. Constr. Steel Res, 65(10-11), 1954-1963.

Viest IM (1956). Investigation of stud shear connectors for composite concrete and steel T-beams. J Am Concr Inst, 27(8), 875-91.

Wang Q (2013). Experimental research on mechanical behavior and design method of stud connectors. $\mathrm{PhD}$ thesis, Tongji University, Shanghai, China.

Wilamowski BM, Irwin JD (2011). The industrial electronics handbook: Intelligent Systems. CRC Press, Boca Raton (FL), USA.

Xu C, Sugiura K, Masuya H (2015). Experimental study on the biaxial loading effect on group stud shear connectors of steel-concrete composite bridges. J. Bridg. Eng, 20(10), 1-14. 
Abambres M, He J (2019). Shear Capacity of Headed Studs in

Steel-Concrete Structures: Analytical Prediction via Soft Computing, hal-02074833

(C) 2019 by Abambres M, He J (CC BY 4.0)

Xue DY, Liu YQ, Yu Z, He J (2012). Static behavior of multi-stud shear connectors for steel-concrete composite bridge. J. Constr. Steel Res, 74(July), 1-7.

Xue W, Ding M, Wang H, Luo Z (2008). Static behavior and theoretical model of stud shear connectors. J Bridge Eng, 13(6), 623-34.

Zhou A, Dai H, Liu Q (2007). Experiment on ultimate bearing capacity and shear rigidity of stud connectors. Industrial Construction, 37(10), 84-87 (in Chinese).

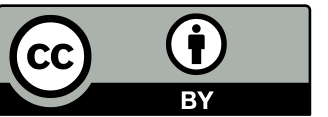

(C) 2019 by Abambres M, He J. Open access publication under the terms and conditions of the Creative Commons Attribution 4.0 (CC BY 4.0) license (http://creativecommons.org/licenses/by/4.0) 